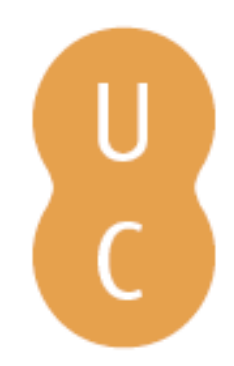

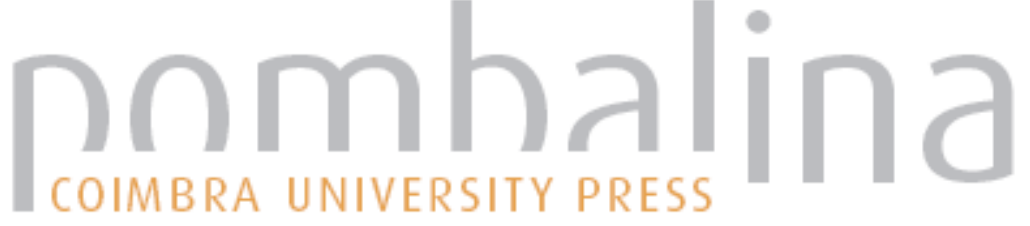

\section{Da Monarquia à República}
Autor(es):
Brandão, José Luís
Publicado por: Imprensa da Universidade de Coimbra
URL persistente:
URI:http://hdl.handle.net/10316.2/36911
DOI:
DOl:http://dx.doi.org/10.14195/978-989-26-0954-6_3

Accessed : $\quad$ 26-Apr-2023 16:02:18

A navegação consulta e descarregamento dos títulos inseridos nas Bibliotecas Digitais UC Digitalis, UC Pombalina e UC Impactum, pressupõem a aceitação plena e sem reservas dos Termos e Condições de Uso destas Bibliotecas Digitais, disponíveis em https://digitalis.uc.pt/pt-pt/termos.

Conforme exposto nos referidos Termos e Condições de Uso, o descarregamento de títulos de acesso restrito requer uma licença válida de autorização devendo o utilizador aceder ao(s) documento(s) a partir de um endereço de IP da instituição detentora da supramencionada licença.

Ao utilizador é apenas permitido o descarregamento para uso pessoal, pelo que o emprego do(s) título(s) descarregado(s) para outro fim, designadamente comercial, carece de autorização do respetivo autor ou editor da obra.

Na medida em que todas as obras da UC Digitalis se encontram protegidas pelo Código do Direito de Autor e Direitos Conexos e demais legislação aplicável, toda a cópia, parcial ou total, deste documento, nos casos em que é legalmente admitida, deverá conter ou fazer-se acompanhar por este aviso.

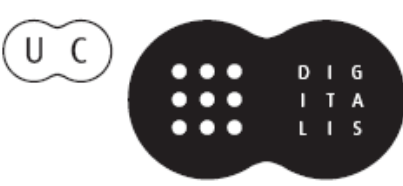


JOSÉ LUÍS BRANDÃO FRANCISCO DE OLIVEIRA (COORD.)

IMPRENSA DA

UNIVERSIDADE

DE COIMBRA

COIMBRA

UNIVERSITY

PRESS
HISTÓRIA DE
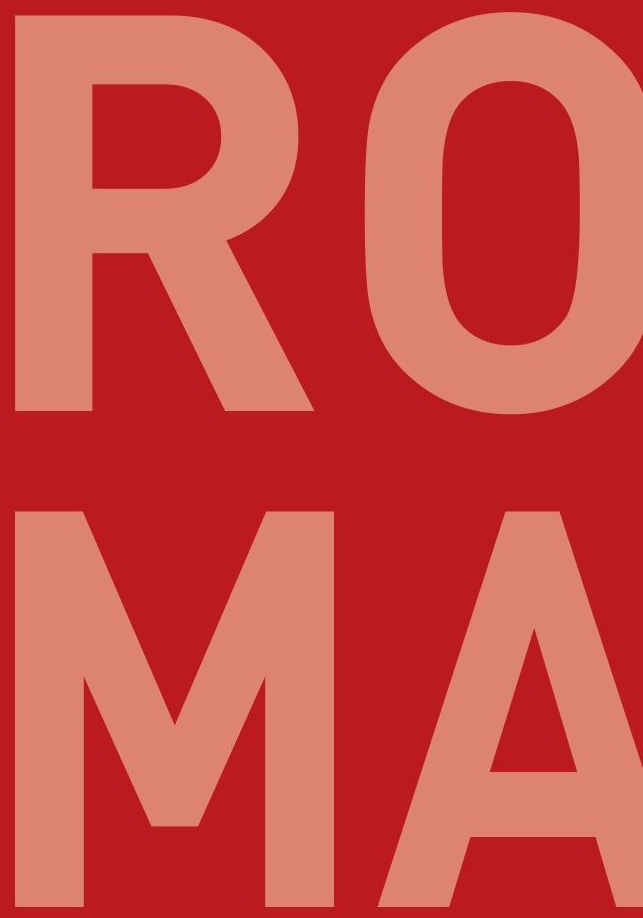

ANTIGA

VOLUME I

DAS ORIGENS À

MORTE DE CÉSAR 


\section{DA MONARQUIA À REPÚBLICA}

José Luís Brandão

Universidade de Coimbra

Centro de Estudos Clássicos e Humanísticos

Sumário: A tradição romana sobre o fim da Monarquia e sua crítica. A figura de Lars Porsena e a mobilidade de guerreiros e aristocratas em finais do século VI. A transformação dos órgãos do governo. Os primeiros anos da República. A controvérsia sobre o direito de apelo. Os fasti e a dedicação do templo de Júpiter no Capitólio. A questão etrusca.

O estudo do início da República, por estar inserido numa fase pouco documentada e lendária da história de Roma, deixa em aberto diversas questões que já os antigos em grande parte colocavam. Com efeito, há problemas cronológicos, há suspeita de efabulação novelística dos heróis e dos seus feitos, há incongruências entre o apoio do rei Porsena a Tarquínio e as guerras em que os Romanos se veem envolvidos, e entre a tradição heroica da resistência a Porsena e as informações sobre a sua efetiva captura de Roma. Além disso, do ponto de vista constitucional, não há certezas sobre os órgãos do governo no início. Também a questão etrusca é hoje redimensionada: insiste-se mais na influência bilateral do que no concreto domínio. 


\section{A tradição sobre o fim da monarquia}

A tradição romana atribuía o fim da Monarquia romana a um drama familiar que levou a uma revolta palaciana envolvendo confronto entre pessoas próximas do último rei, Tarquínio o Soberbo. Trata-se do relato da tragédia de Lucrécia, violada, segundo a lenda, por Sexto, filho daquele rei, depois de o receber em sua casa como hóspede e familiar. Consumado o estupro, a jovem convocou o esposo, Tarquínio Colatino, o pai, Terêncio, e os amigos Lúcio Júnio Bruto e Públio Valério Publícola, a quem relatou o crime, suicidando-se de seguida com as célebres palavras: "para que nenhuma mulher viva desonrada à sombra do exemplo de Lucrécia». Os presentes, horrorizados, decidiram expulsar Tarquínio e não mais aceitar a presença de reis na cidade, pelo que, em vez deles, foram eleitos dois cônsules: Lúcio Júnio Bruto e Tarquínio Colatino¹.

As fontes apresentam o ano 1 da República como bastante atribulado. Depois de descoberta uma conjura para reconduzir Tarquínio, em que participaram os sobrinhos de Colatino e os filhos de Bruto, se estes foram executados por ordem inexorável do pai, Colatino parecia pouco determinado, pelo que acabou por renunciar ao cargo ou ser afastado por Bruto e banido de Roma por carrregar o nome de Tarquínio. Para o seu lugar foi eleito Públio Valério, cognominado Publícola. Bruto foi morto em combate contra as tropas de Tarquínio, e Publícola governaria algum tempo sozinho, de forma a impor algumas leis consideradas, no entanto, populares. Foi depois eleito para o lugar de Bruto Lucrécio, pai de Lucrécia, que morreria poucos dias depois. Finalmente foi eleito Marco Horácio a quem coube, segundo a tradição, dirigir o rito de sagração do templo de Júpiter do Capitólio. Associada ao início da República aparece, assim, também a figura de Valério Publícola, que acumula consulados (508, 507, 506, 504) e desempenha o papel de importante legislador democrático (Plutarco emparelha-o com Sólon nas Vidas Paralelas), e a de Horácio, ligado à inauguração do templo de Júpiter do Capitólio que a maior parte da tradição colocava também em 509 a.C..

\footnotetext{
${ }^{1}$ Liv. 1.57-59; D.H. 4.64-67.
} 
O ceticismo em relação a estes relatos já vem da antiguidade e acentuou-se nos historiadores modernos. A tradição literária retrata Tarquínio segundo os lugares-comuns tradicionais aplicados aos retratos dos tiranos. A história da expulsão do rei, impulsionada pela ofensa a Lucrécia, lembra o relato da queda da tirania dos Pisitrátidas em Atenas (Th. 6.53-59). As personagens envolvidas têm um caráter romanesco de conto popular, e o suicídio da jovem desonrada pode simbolizar um sacrifício expiatório ${ }^{2}$. A saga foi sendo retocada pela tradição oral e pode até ter origem dramática. Por outro lado, não se entende muito bem como é que são os sucessores ao trono que lideram o golpe; como é que, sendo da família dos Tarquínios, são eleitos cônsules Colatino e Bruto; ou como é que Colatino teve, depois, de ser banido da cidade por pertencer à família de Tarquínio e Bruto não ${ }^{3}$.

Quanto às fontes, sobre esta época temos três textos principais: Dionísio de Halicarnasso, Tito Lívio e Plutarco (Vida de Publícola), que, por sua vez se baseiam em historiadores do final da República. Mas temos de pôr em questão os dados que teriam estes autores sobre os primeiros tempos e como os interpretariam. Em comparação com os Gregos, a historiografia em Roma inicia-se consideravelmente tarde ${ }^{4}$ : segundo Dionísio de Halicarnasso (1.6.2), os primeiros historiadores foram Fábio Pictor e L. Cíncio Alimento, que, em finais do século III a.C. escreveram a história de Roma em grego. E seria baseada na transmissão oral, que se considera fiável apenas durante cerca de três gerações. De qualquer modo, Fábio Pictor (e, segundo parece, outros historiadores da época) debruça-se sobre o período da fundação e os tempos mais próximos de si, descartando a fase da República primitiva. Este senador, que pertence àquela elite dos nobiles que se desenvolveu no decorrer do século IV, regista em grego ${ }^{5}$ os feitos dos Romanos, para celebrar a gesta da classe a que pertence e os valores que cultiva. Nos Annales de L. Calpúrnio Pisão Frugi e de Énio, a Monarquia é tratada de modo

\footnotetext{
${ }^{2}$ Lucrécia expia um crime de que não tem culpa, mas que à luz da lei familiar implica um castigo; antecipação de uma condenação provável. Vide Voisin 1990 257-261.

3 Como salienta Cornell 1995215 ss.

${ }^{4}$ Vide Gabba 2000 61ss.

5 Fábio Pictor dirige-se a um público grego, especialmente ao da Magna Grécia, talvez para combater a propaganda dos historiadores filocartagineses. Vide Gabba 2000 28-30; 61-68.
} 
mais detalhado do que os primeiros tempos da República, e a informação só volta expandir-se para o período das Guerras Samnitas. O princípio da República parece ter sido esquecido, uma vez que as instituições foram suplantadas por desenvolvimentos políticos posteriores. Constatamos, no entanto, que, em Lívio e em Dionísio de Halicarnasso, a informação sobre o início da República se apresenta já mais detalhada. Tudo indica, pois, que os relatos que possuímos sobre esse período inicial se baseiam em fontes que, no final da República, interpretaram os acontecimentos à luz dos problemas políticos que viviam ou projetaram retroativamente acontecimentos do momento em que escreviam, marcados pelos conflitos entre optimates e populares ${ }^{6}$, ou efabulavam visando glorificar as suas linhagens ${ }^{7}$.

\section{Quem era Lars Porsena?}

A tradição estabelece, pois, uma transição imediata, mas é provável que um período de instabilidade tenha existido antes de as instituições republicanas funcionarem. A tradição patriótica diz que Porsena era um rei etrusco que veio tentar restabelecer Tarquínio no trono, mas que acabou por desistir ao ver a coragem dos Romanos, patente em exemplos heroicos de Múcio Cévola, Horácio Cócles ou a jovem Clélia ${ }^{8}$. Mas nenhum general desistiria de uma guerra comovido pela determinação do adversário. Apesar da tradição generalizada, duas fontes antigas contam que Porsena tomou de facto Roma: Tácito (Hist. 3.72) e Plínio (Nat.

\footnotetext{
${ }^{6}$ Os responsáveis por esta expansão dos relatos do início da República poderão ter sido Gneu Gélio, autor de uns annales (c. 130 a.C.) carregados de pormenores de antiquária, e Licínio Macro (Macer), famoso tribuno de 73, que se terá interessado pelo desenvolvimento das instituições da plebe, com o intuito de glorificar os seus antepassados plebeus. Vide Raaflaub 2005 1-5.

${ }^{7}$ Valério Ântias, escritor do tempo de Sula, pode ser o responsável pelo desenvolvimento da figura de Publícola, na tentativa de engrandecer a estirpe dos Valérios: pode ser, por exemplo, o inventor dos três consulados contínuos de Valério Publícola, do consulado do irmão deste no quarto ano, de Publícola de novo no quinto e dos feitos de Valéria, filha daquele, como sugere Alföldi 196382 e n. 6. É igualmente possível que Valério Messala Corvino tenha, nas suas Memórias ou noutra obra, engrandecido o seu antepassado, uma vez que o próprio Plutarco reporta a Publícola a nobreza desta linhagem (Plu. Publ. 24.3): vide Flacelière, Chambry \& Juneaux 1961 54-55.
}

8 Cf. Liv. 2.9-15; Plu. Publ. 16-19. 
34.139). É bem possível que a Monarquia tenha caído na sequência da tomada de Roma por Porsena, e que Tarquínio, deposto ou em fuga, tenha encontrado apoio junto dos Latinos9. Os Romanos tinham um tratado de cooperação militar com os povos latinos renovado pouco antes por Tarquínio ${ }^{10}$. Porsena deve ter vindo, portanto, quebrar a unidade que se estabelecera no Lácio. Os Latinos renovaram a Liga Latina, centrada agora em volta do santuário de Arícia (e não já no do Aventino, fundado por Sérvio Túlio segundo a tradição) e Roma aparece excluída deste pacto por estar nas mãos de Porsena ${ }^{11}$. Segundo a chamada Crónica de Cumas $^{12}$, a tentativa de Porsena de controlar o Lácio terá levado à batalha de Arícia em 504, na qual os Latinos, apoiados por Aristodemo de Cumas, derrotaram Arrunte, filho de Porsena. Depois destes desenvolvimentos, os Romanos viram-se frente a frente com uma coligação latina que apoiava as pretensões de Tarquínio e que levou à batalha do Lago Regilo, em 499 (segundo Lívio, 2.19-20) ou 496 (segundo Dionísio de Halicarnasso, 6.2ss), conflito em que os Romanos venceram, impondo a sua hegemonia na Liga Latina ${ }^{13}$.

Provavelmente a atividade bélica do rei de Clúsio tem que ver com movimentos de povos que perturbaram a Itália central no final do século VI a.C. Na época era comum senhores de guerra de origem aristocrática cruzarem as fronteiras com os seus bandos de clientes ou companheiros (sodales). Parece ser esse o caso por exemplo do massacre dos 300 Fábios apanhados numa emboscada na guerra contra Veios em 479.

9 Como sustenta Alföldi 1963 51-52.

10 Cf. Liv. 1.52 .

$11 \mathrm{O}$ número de povos que integraram esta confederação varia segundo os autores: Dionísio de Halicarnasso (5.61.2) diz que foram todos os Latinos, e Lívio (2.18.3; cf. Plin. Nat. 3.69) diz que foram 30 povos. Mas Dionísio (5.61.3), no elenco das cidades, apresenta 29, excluindo Roma (cf. 5.50.2).

12 Os kumaika atribuídos a Hipéroco - obra a que pertenceria um excerto sobre a vida do tirano de Cumas, Arsitodemo o Efeminado, interpolado pelo próprio Dionísio no seu texto (7.3-11) e que não parece ter sofrido a contaminação dos escritores de Annales romanos. Serviria de base para a datação dos acontecimentos no Lácio no final do séc. VI a.C. Vide Alföldi 196356 ss; Gabba 2000 32-33.

13 Pelo menos no entender das fontes tardias. Vide Cornell 1995 297-298; Forsythe 2005 147-149. 
Não se trataria pois de membros da mesma família em sentido restrito, mas mais provavelmente dos Fábios e dos seus clientes. Uma tradição etrusca conhecida dos Romanos reportava as aventuras guerreiras dos irmãos Aulo e Célio Vibena e de Mastarna, presentes me representações, como um fresco de um túmulo de Vulcos (François Tomb), já referido no capítulo anterior ( $\$ 2.1$.). O imperador Cláudio conhecia tal tradição e faz coincidir Mastarna com o rei Sérvio Túlio. A interpretação do nome Mastarna (como derivado de magister 'comandante') parece conotá-lo com o cargo de ditador (magister populi) e seu colaborador directo (magister equitum), pelo que parece sugerir que se trate de uma espécie de magistrado de uma fase muito incipiente da República. Mas as dúvidas são muitas ${ }^{14}$.

Uma evidência arqueológica em Sátrico vem corroborar estas "confrarias" aristocráticas de guerreiros. Trata-se do denominado Lapis Satricanus (A pedra de Sátrico), descoberta em 1977, que contém uma inscrição datada de cerca de 500 a.C. onde se refere a dedicação a Marte por parte dos companheiros (sodales) de Poplios Valesios, que se poderia identificar com Públio Valério Publícola, um dos cônsules referidos para os primeiros tempos da República. Trata-se do testemunho de um grupo que se identifica não por referência a um estado ou a uma etnia mas como companheiros de um líder. Aquele achado veio também reforçar a existência histórica de Publícola, figura que alguns consideravam lendária. Também Porsena poderia muito bem ser um destes senhores da guerra, embora se reconheça que era um rei de prestígio na Itália e até se lhe atribua uma estátua arcaica existente no foro de Roma ${ }^{15}$.

A esta distância, o que poderemos dizer é que por volta de 500 a.C. ocorreu uma transformação de um regime monárquico para o regime republicano. É difícil dizer o ano, se é que ocorreu só num ano; é difícil reconstituir os factos que levaram a esta transformação - se foi um conflito dinástico que Porsena aproveitou em seu benefício, ou se foi uma transformação lenta e natural, acaso favorecida por problemas económicos

\footnotetext{
14 Vide Cornell 1995 130-150 e 233-235.

15 Cf. Plu. Publ. 16.1 e 19.10.
} 
e conflitos sociais $^{16}$. Havia então na Itália Central uma tendência para a aristocracia tomar o lugar dos reis, pelo que aproveitavam a oportunidade quando o trono vagava ${ }^{17}$. Apesar da disparidade dos relatos, as fontes literárias, gregas e romanas, bem como as evidências arqueológicas, apontam para um final violento da monarquia.

\section{Metamorfose dos órgãos do governo}

As fontes apresentam a mudança de forma simplista: o rei é substituído por dois cônsules Bruto e Colatino. Tito Lívio (1.60.4) diz que os cônsules foram eleitos nas assembleias por centúrias, cuja criação era atribuída a Sérvio Túlio. Dionisio de Halicarnasso (4.84.5) salienta que a eleição se fez segundo o costume dos antepassados. Os cônsules eram magistrados epónimos (davam o nome ao ano), detentores de imperium, pelo que podiam comandar exércitos, e eram eleitos nos comitia centuriata, dada a natureza militar. Detinham poder igual (eram collegae) e podiam boquear-se um ao outro. Como insígnias tinham a toga praetexta (toga ornada de uma faixa de púrpura), a cadeira curul e eram acompanhados pelos litores, os 12 oficiais que transportavam os feixes de varas (fasces), símbolo do poder de castigar (inicialmente os fasces eram usados ativamente nas punições, como se vê, por exemplo, na Vida de Publícola de Plutarco ${ }^{18}$ ). No meio das varas estava encastrado um machado, que mais tarde seria suprimido dentro da cidade em resultado da aprovação do direito de apelo (provocatio ad populum) perante uma decisão de um magistrado.

Em época de crise podia nomear-se um ditador, designado por um dos cônsules. Este reunia em si o poder dos dois cônsules, pelo que tinha também 24 lictores, mas o seu governo limitava-se habitualmente a metade do

${ }^{16}$ Vide Cornell 1995 218. Forsythe (2005 153-155) sugere que, com a tomada de Roma, Porsena tenha dividido o poder entre a família real, representada por Colatino, e Bruto. Com a derrota de Arícia, Porsena perdeu as suas aspirações, e as famílias aristocráticas mantiveram o poder entre dois chefes.

17 Como afirma Alföldi 1963 77-78.

18 Cf. Plu. Publ. 6.4. 
tempo, isto é: seis meses. O ditador era também designado por magister populi (comandante do povo) e, devido a esta função de comandante de infantaria, tradicionalmente não podia montar a cavalo sem permissão19. Por seu turno, nomeava um subordinado, o magister equitum (comandante da cavalaria). Embora na sua maior parte fossem nomeados ditadores para resolver situações de grande perigo na guerra (rei gerendae causa), também serão de futuro escolhidos para outras funções específicas, como promover eleições na ausência dos cônsules, lidar com distúrbios civis e mesmo para realizar ritos propiciatórios dos deuses em épocas de calamidades. Há quem sugira que a nomeação do magister populi (mais tarde chamado dictator) pode já vir do tempo da monarquia - seria nomeado pelo rei quando este não podia estar presente no acampamento militar por razões de saúde ou por ter de cumprir funções políticas ou religiosas em Roma $^{20}$. Os autores antigos concordam que Lárcio foi o primeiro ditador, em datas que variam entre 501 e 497 a.C ${ }^{21}$.

Para as funções religiosas que o rei detinha, criou-se (ou manteve-se) o rex sacrorum, encarregado de desempenhar na regia (nome que significa 'casa do rei') determinados rituais antigos que se apresentavam estranhos para os historiadores do final da República. É possível que este 'rei para os assuntos sagrados' já existisse desde o tempo da Monarquia, pelo menos da sua última fase do século VI a.C., em que Roma, em confronto com um sistema anterior, parece ter sido governada por tiranos ${ }^{22}$.

Os historiadores modernos perceberam que a palavra consul salienta a natureza colegial da função (o prefixo cum- significa ação em conjunto) e alguns, na sequência de De Martino, sugerem que talvez seja

\footnotetext{
19 Vide Lintott 1999 109-113.

20 Vide Mazzarino 1992 179-184; Gjerstad 1967 24-26. Este autor, procurando acertar a tradição dos 7 reis com os dados da arqueologia, estende a monarquia até meados do século V (em que o rei seria acompanhado dos magistrados epónimos - os praetores), com base na datação das construções e instituições atribuídas aos últimos três reis: como o templo de Júpiter no Capitólio; a muralha serviana, as reformas de Sérvio Túlio etc. Apesar da coexistência de reis e magistrados epónimos ter paralelos na Grécia, tal teoria não vingou. Vide Cornell 1995 221-223.

21 Vide Broughton 195110.

22 Vide Cornell 1995 232-236.
} 
uma criação de 367 (em resultado das conquistas da plebe tratadas no capítulo seguinte) ${ }^{23}$. Parece que, no início, seriam, segundo Festo (249 L), designados por praetores (de prae ire: 'ir à frente', 'comandar'), dada a sua função de comandantes militares.

A tradição pressupõe que os magistrados superiores eram dois desde o início da República, com igual autoridade, mas pode ter sido esquecido um modelo anterior. A própria substituição dos cônsules mortos em exercício por suffecti ('substitutos') logo no primeiro ano da República parece ser antecipação de um modelo consagrado mais tarde. Uma discutida passagem de Lívio (7.3) fala da restauração da prática antiga (lex uetusta) de nomear um ditador para colocar um prego no templo do Capitólio, uma observância que, segundo o historiador, era no início levada a cabo pelo praetor maximus. Ora o superlativo (maximus) parece indicar mais do que dois ${ }^{24}$. Outros acham que tal não era forçoso. A referência a praetores maiores e praetores minores no augurium salutis (Festo $152 \mathrm{~L}$ ) parece explicar-se por ser uma fórmula arcaica em que praetor equivale genericamente a magistratura. E o atributo Maximus poderia ser para o distinguir dos restantes magistrados 25 ; ou para distinguir o que detinha os fasces no início do ano, no momento de colocar o referido prego na parede do templo ${ }^{26}$.

Outra hipótese para a transição seria a substituição do rei pelo ditador (o magister populi), que por sua vez se fazia acompanhar do mestre de cavalaria (o magister equitum) ${ }^{27}$; e, como os dois nomes apareciam emparelhados na lista (os Fasti), poderiam ter sido interpretados como cônsules pelos historiadores ${ }^{28}$. Mas pode-se argumentar que a colegialidade era um

23 Vide Forsythe 2005 151-152. Poderá ter sido modelada sobre praesul, correspondente religioso de praetor, em que consul patenteia pela mudança de prefixo ( $c u m$ em vez de prae) a evolução constitucional, salientando a colegialidade da função. Vide Heurgon 1969164.

${ }^{24}$ Por exemplo 3 (segundo De Sanctis), de acordo com as 3 legiões existentes no início.

25 Praetor maximuus seria traduzido para grego como strategos bypatos. E bypatos é a palavra grega usada para traduzir cônsul. Vide Mazzarino 1992187.

26 Como assinala Forsythe 2005152.

27 Tese de Beloch e De Martino, apud Cornell 1995228.

28 É a hipótese de Alföldi 1963 81. Vide Gagé 1976 88. Segundo Mazzarino 1992 183-191, a revolução da segunda metade do século VI consistiu no facto de o rex, velho resquício da sociedade patriarcal, ter ficado restrito a funções sacrais, e de o governo ter começado a ser dirigido pelo magister populi e magister equitum - cargos que depois evoluíram para 
princípio antiquíssimo e, portanto, os magistrados superiores poderão ter sido sempre dois ${ }^{29}$. Não é contudo improvável que em 509/8 estivesse um praetor maximus a encabeçar os colegas e que acabasse por ser esquecido devido aos desenvolvimentos posteriores da instituição do governo ${ }^{30}$. De qualquer modo, é possível que, nos primeiros dois séculos da denominada República, não houvesse apenas um sistema político em Roma ${ }^{31}$.

Bruto teve o mérito de ser considerado o fundador da liberdade republicana porque era o primeiro da lista dos cônsules. Mas há quem proponha a remoção de Lucrécio, Valério e Horácio do primeiro ano da República. Segundo Forsythe (2005 154-55), os outros foram adicionados posteriormente para fazer coincidir a provocatio (que muitos consideram uma antecipação da lei de 300) e a dedicação do templo do Capitólio com o primeiro ano da República.

\section{O direito de Apelo}

Ao primeiro ano de governo remonta, segundo a tradição, o direito de apelo para o povo (provocatio ad populum), atribuído originariamente a Valério Publícola. Causou suspeita que esta lex Valeria aparecesse formulada

dois praetores com igual poder, deixando a possibilidade de retorno ao magister populi (ou dictator) como magistratura extraordinária, para ocasiões críticas.

29 É o que pensa Giovannini 1993 93. A ditadura nunca foi na época histórica uma magistratura independente (os cônsules que o nomeavam mantinham o cargo) e as competências do ditador limitavam-se a um campo bem definido. Para este autor, a passagem da Monarquia à República tinha forçosamente de contar com a aprovação augural; o decreto de criação dos primeiros magistrados republicanos, precedente para as eleições seguintes, deve ter sido conservado, na tradição escrita ou oral. Vide Forsythe 2005153.

30 Vide Heurgon 1969 162-163; Wiseman 199823.

31 É o que pensa Flower 2005 35-57. A autora apresenta uma hipótese de periodização, tentando reconstruir as fases em que existiram diferentes modelos. A primeira fase, pré-republicana no caráter, é a da experimentação com largos quadros de magistrados difíceis de definir num padrão e não imitados na República tardia. A segunda fase, com início em 454 (data que considera mais provável da dedicação dos templos do Capitólio e do Aventino) e termo em 451/0, seria a fase proto-republicana. A terceira fase consistiria em experimentação política: a alternativa dos tribunos militares. A partir de 367/6, temos a substituição dos quadros de magistrado por dois cônsules anuais, cargo partilhado entre patrícios e plebeus: entre 367 e 300 aparece como que uma segunda República em que os nobiles se consolidam no poder. 
em três ocasiões: 509, 449 e 300 a.C. Tende-se a aceitar como genuína a última. Mas parece que se está a confundir prouocatio ad populum com uma conquista da plebe: o direito dos tribunos de se oporem a uma decisão de um magistrado mesmo que fosse legal (o ius auxilii), tratado por N. S. Rodrigues no capítulo seguinte. Independentemente de o relato poder ser ficcionado, e etiológico, há indicações de que o direito de apelo para o povo de todos os cidadãos contra as decisões dos magistrados já existia há muito ${ }^{32}$, e estava fora da alçada dos tribunos da plebe. É um direito não apenas da plebe, mas do populus, isto é de qualquer cidadão, enquanto cidadão romano, patrício ou plebeu, contra a arbitrariedade de um magistrado; e é um direito válido mesmo fora da cidade, onde os tribunos já não tinham jurisdição ${ }^{33}$. Por outro lado, não se pode afirmar com segurança que as três leis eram de facto idênticas. Mas também é verdade que poderia tratar-se mais de um costume do que legislação efetiva ${ }^{34}$. O propósito da lei de 449 seria não a garantia de apelo em si, mas reforçá-lo com a proibição de criar de magistraturas que não estivessem submetidas a tal direito, como assinala Lívio (3.55.3), pelo que tal lei (de 449) pressupõe que o direito de apelo já existia, como parece implícito nas XII tábuas (9.1-2). Além disso, era hábito dos Romanos legislarem repetidamente sobre os mesmos assuntos, incorporando determinações anteriores, garantindo, deste modo, dinamismo à constituição republicana ${ }^{35}$.

\section{Os fasti e a sagração do templo de Júpiter do Capitólio}

Havia formas de contar os anos da República: uma era pois a lista dos cônsules. O facto de os cônsules darem o nome ao ano deve ter facultado aos escritores de Annales uma ideia aproximada de quando a República começou. As listas de cônsules chegam-nos através de Dionísio

32 Tito Lívio (1.26) e Cícero (Rep. 2.31.54) fazem-na mesmo remontar à época monárquica.

33 Vide Giovannini 1993 93-96.

${ }^{34}$ Lintott (1999 33-34) sugere que se poderia tratar mais de uma medida empregue por um indivíduo ameaçado para congregar apoio entre o povo do que propriamente criação de leis.

35 Vide Poma 1984 305-09; Cornell 1995 276-277. 
de Halicarnasso, Tito Lívio, Diodoro Sículo e a inscrição colocada por Augusto no foro, conhecida como Fasti Capitolini. Estas fontes devem basear-se nos registos anuais dos Pontífices, compilados no século II a.C. nos Annales Maximi36.

Outro método de contagem estava dependente da tradição romana que fazia coincidir a sagração do Templo de Júpiter no Capitólio com o primeiro ano da República. A notícia de Tito Lívio (7.3.5ss) de que desde a dedicação do templo do Capitólio se colocava anualmente (a 13 de setembro, aniversário da sagração) um prego na cella de Minerva, cruza-se com uma informação de Plínio-o-Velho (Nat. 33.1.19), segundo o qual, em 304, o edil Gneu Flávio contou 204 anos da dedicação do Templo de Júpiter, o que aponta para a data de 508 a.C, precisamente um ano depois da inauguração. Há quem pense que é demasiada coincidência - é perfeito demais para ser verdade.

Se a tradição plasmada em Lívio (2.8) e Plutarco (Publ. 14) coloca a dedicação do templo do Capitólio no primeiro ano da República, Tácito (Hist. 3.72) e Dionísio de Halicarnasso (3.69.2) deslocam-na para o terceiro ano, no segundo consulado de Horácio, o que faz suspeitar que se lhe tenha atribuído um primeiro consulado em 509 para fazer coincidir a consagração com o início do novo sistema governativo ${ }^{37}$. Outros acham que o templo ainda foi consagrado em 509, no tempo da Monarquia 38 .

Há quem considere a lista de cônsules fraudulenta, com nomes inseridos artificialmente, para fazer coincidir o início da República com o número dos pregos do templo e com a data tradicional de 509. Alguns nomes podem ter sido inseridos para suprir o lapso entre o último rei e os primeiros magistrados da República ${ }^{39}$. Com efeito, a presença entre os cônsules da lista de 509 a 445 de nomes que sabemos serem plebeus

36 Cf. Serv. A. 1. 373; Cic. de Orat. 2.52. Vide Gabba 200035.

37 Vide Forsythe 2005154.

38 Segundo Alföldi 1963 78-79; 351, o templo foi consagrado em 509 ainda por Tarquínio, rei que teria sido expulso em 505. E o nome de M. Horácio que, segundo as fontes, se lia na arquitrave seria o de M. Horácio tribunus militum consulari potestate que levou a cabo a nova dedicação em 378, depois do saque gaulês.

39 Para Alföldi 1963 77-84 a lista só é fiável a partir de 504. Vide Heurgon 1969 158-161. 
na República tardia coloca alguns problemas: não se ajusta à tradição de que o primeiro cônsul plebeu foi eleito em 366 a.C. Várias teorias se esforçaram por explicar estas discrepâncias. Suspeita-se que tais nomes sejam forjados por redatores plebeus dos Annales dos pontífices. Mas pode acontecer que certas famílias plebeias tenham adotado nomes patrícios de famílias extintas, e era comum famílias patrícias apresentarem ramos plebeus ${ }^{40}$. Além disso, vê-se que os cognomina destes primeiros magistrados são, na verdade, alcunhas, com um sentido pejorativo, como é o caso de Brutus 'estúpido', mas também de Publícola41, cuja inserção na lista de cônsules (fasti) pode ser tardia.

Mas, numa abordagem geral, pode considerar-se que os erros das listas de cônsules são menores. A despeito de algumas variações de fonte para fonte, a cronologia parece no essencial ser fiável, uma vez que há confirmação de fontes independentes. Todas as sequências de cônsules apontam um começo para o final do século VI a.C., entre 509 e 502. Políbio (3.22.1-2) estabelece que os primeiros cônsules, Bruto e Horácio, exerceram a magistratura 28 anos antes da travessia de Xerxes para a Grécia, provavelmente a pensar no ano da batalha de Salamina (480 a.C.). Dionísio de Halicarnasso (5.1.1) diz que a República teve início no ano da $68^{\text {a }}$ Olimpíada (508/507 a.C.). Estes autores podem ter sido contaminados pela tradição romana, mas uma fonte grega acolhida por Dionísio refere a batalha de Arícia em 504 a.C. ${ }^{42}$ E, apesar das divergências de alguns anos, um processo de datação por referência à expulsão do rei parece ser muito antigo, visto que aparece em documentos anteriores à invasão gaulesa de 390 a.C. como testemunha Dionísio ${ }^{43}$. Apesar das inserções ou

40 Vide Cornell 1995 218ss; Forsythe 2005 155-157.

41 Vide Alföldi 1963 83-84. Este autor considera que a justificação para o nome como expressão do seu desvelo para com o populus é errada, porque populus nos primeiros tempos incluía também o senado; assim como é também forjada a interpretação plebicola ('que corteja a plebe').

42 D.H. 7.5. E referem e a conquista de Roma pelos Gauleses em 387 ou 386 a.C. (D.H. 1.74.4), pouco depois da data tradição 390 a.C.

43 D.H. 1.74.5. O documento refere um ato censório ocorrido no segundo ano antes da conquista de Roma pelos Gauleses e que apresenta a datação de 119 anos depois da expulsão do rei. Vide Gabba 2000 151-158. 
omissões nas listas dos cônsules e das diferenças dos relatos, a tradição sobre o início da República seria forte e era controlada por autoridades religiosas que, conhecendo bem o essencial da tradição de cor, a poderiam refazer em caso de destruição de documentos nas catástrofes.

\section{Etruscos}

Vários autores assumem que o fim da Monarquia marcou o ocaso de um governo etrusco de Roma, como se se tratasse de uma libertação da opressão estrangeira. Esta opinião implica que o reino dos Tarquínios consistiu num domínio etrusco de Roma e aparece a par do preconceito de que foi um poder etrusco a trazer a prosperidade a Roma, como vimos no capítulo anterior. Tal ideia moderna está hoje posta em causa, sobretudo por T. J. Cornell. O autor demonstra cabalmente que não há vestígios literários ou documentais de que assim tenha acontecido. Não houve expulsão dos Etruscos de Roma. As fontes literárias referem apenas a expulsão da família dos Tarquínios (que além disso seriam de ascendência grega); e não por ele ser etrusco, mas por ser um tirano. Não houve qualquer rejeição da cultura (pelo contrário, foram adotados símbolos e práticas divinatórias) nem se observa diminuição do comércio com a região etrusca, até meados do século V (e então devido a uma aparente recessão no Mediterrâneo Ocidental que afetou também o comércio com a Grécia) ${ }^{44}$.

Em suma, a República parece ter tido origem num tempo de convulsão política e social no Lácio de finais do século VI, acontecimentos provavelmente embelezados mais tarde pela tradição patriótica. O ódio com que os Romanos sempre se referiam ao regnum e o ritual arcaico do regifugium ('fuga do rei') podem radicar nesses conflitos. É difícil saber se a transição se fez imediatamente de um rei para dois cônsules (ou pretores) eleitos anualmente, como sugere a tradição literária, ou se houve instituições alternativas de transição. Mas era nesse momento

44 Vide Cornell 1995 223-226; Rocha Pereira 2009 23-24. 
que os Romanos viam, ou queriam ver, quando mais tarde escreveram a sua história, a génese dos mais caros princípios republicanos, como as eleições dos magistrados, a colegialidade, o direito de apelo; além da inauguração do principal centro religioso da Urbe: o templo de Júpiter do Capitólio, intimamente associado à contagem dos anos da República.

\section{Tábua Cronológica}

509 a.C. - Data tradicional da implantação da República

504 a.C. - Batalha de Arícia

499. C. - Batalha do Lago Regilo

\section{Bibliografia}

Alföldi, A. (1963), Early Rome and the Latins, Ann Arbor.

Broughton, T. R. \& Patterson, M. (1951), The Magistrates of the Roman Republiic I, New York. Cornell, T. J. (1995), The beginnings of Rome. London/New York, Routledge.

Flower, H. I. (2010), Roman Republics. Oxford, Princeton University Press

Forsythe, G. (2005), A critical history of early Rome. Berkeley /London, University California Press.

Gabba, E. (2000), Roma Arcaica. Storia e storiografia. Roma, Edizioni di storia e letteratura.

Gagé, J. (1976), La chute des Tarquins e les débuts de la République Romaine. Paris.

Giovannini, A. (1993) "Il passagio dalle istituzioni monarchiche alle istituzioni republicane", in Convegno sul tema "Bilancio critico su Roma arcaica fra Monarchia e Republica". Atti dei Convegni Lincei 100. Roma, Academia dei Lincei, 75-96

Gjerstad, E. (1962), Legends and facts of early Roman history. Lund.

Gjerstad, E. (1967), "The origins of Roman Republic", in Les origines de la République romaine. Vandoeuvres-Genève, 3-30.

Heurgon, J. (1969), The rise of Rome. Translated by James Willis. London.

Leão, D. e Brandão, J. L. (2012), Plutarco. Vidas de Sólon e Publícola. Tradução do grego, introdução e notas. Coimbra, CECH, 2012.

Lintott, A. 1999, The Constitution of the Roman Republic. Oxford, University Press.

Mazzarino, S. (1945/1992), Dalla monarchia allo stato republicano. Milano, Rizzoli.

Olgivie, R. M. (1976), Early Rome and the etruscans. Trowbridge, The Harvester Press.

Poma, G. (1984), Tra legislatori e tirani. Problemi storici e storiographici sull'età delle XII tavole. Bologna, Pàtron Editore.

Raaflaud, K. A. (ed.) (2005), Social struggles in Archaic Rome. New perspectives on the conflict of the orders. Oxford, Blackwell. 
Raaflaud, K. A. (1993), "Politics and society in fifth-Century Rome", in Bilancio critico su Roma arcaica fra Monarchia e Republica. Atti dei Convegni Lincei 100. Roma, Academia dei Lincei, 129-157.

Raaflaud, K. A. (2005), "The conflict of the orders in Archaic Rome: a comprehensive and comparative approach", in Raaflaud, Kurt A.(ed.) (2005), Social struggles in Archaic Rome. New perspectives on the conflict of the orders. Oxford, Blackwell, 1-46.

Rodrigues, N. S. (2005), Mitos e lendas. Roma antiga. Lisboa, Livros e Livros.

Scullard, H. H. ( $\left.{ }^{4} 1980\right)$, Roman world. 753 to 146 BC. London, Methuen.

Voisin, J.-L. (1990), "Deux archetypes de la mort volontaire: lucrece et Horatius Cocles?", in Bloch, R. (org.) La Rome des premiers siècles: legende et histoire. Actes de la table en l'honneur de Massimo Pallontino (Paris 3-4 Mai 1990). Firenze, Olschki, 257-266.

Wiseman, T. P. (1998), "Roman Republic”, GER 14 19-26. 